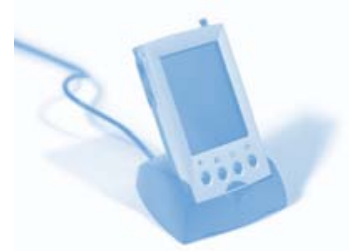

Tom Lemanski*, Ruth Mewis and Tina Overton Department of Chemistry University of Hull Hull

HU6 7RX

*t.lemanski@2004.hull.ac.uk

\section{An introduction to the recent literature on approaches to work-based learning}

\author{
Abstract \\ The term work-based learning is widely used throughout the literature, academia and \\ industry to describe a multiplicity of approaches by which one can learn through work. \\ The complex nature of work-based learning can often lead to confusion when designing \\ courses which aim to implement such an approach. \\ This review will focus on: \\ - The rationale for conducting work-based learning. \\ - The varieties of approaches to work-based learning that are currently implemented. \\ - Student opinions of work-based learning;. \\ - How to resolve any implementation and communication issues.
}

There are many approaches to developing work-based learning modules, courses and projects that utilise learning at, learning for, and learning through work. This paper aims to review the literature in these areas.

\section{Identifying the need}

Many reports identify the need to upskill the workforce,$^{1-3}$ with the Leitch Review of Skills ${ }^{2}$ setting short and long term goals for education in the UK as outlined further within this section. The Cogent Skills Review ${ }^{1}$ analyses in great depth the many aspects affecting the major STEM-based industries. It outlines future priorities for each industry whilst considering the role of Sector Skills Councils in increasing the skills of the workforce within the chemicals, pharmaceuticals, oil and gas, nuclear, polymer and petroleum industries. $^{1}$

The Leitch Review of Skills sets an ambitious target, that by 2020 the UK will be within the top eight worldwide for each skill level, with emphasis on delivering qualifications to a far higher percentage of the workforce. The targets aim for over $90 \%$ of adults qualified to above Level 2 whilst also shifting the balance of skills from Level 2 to Level 3 as well as increasing those with Level 4 qualifications and skills from $29 \%$ to $40 \%$, combined with increasing the number of adult apprenticeships. ${ }^{2}$ The skill levels are defined by the National Qualifications Framework (NQF), which is illustrated in Figure 1. ${ }^{4}$

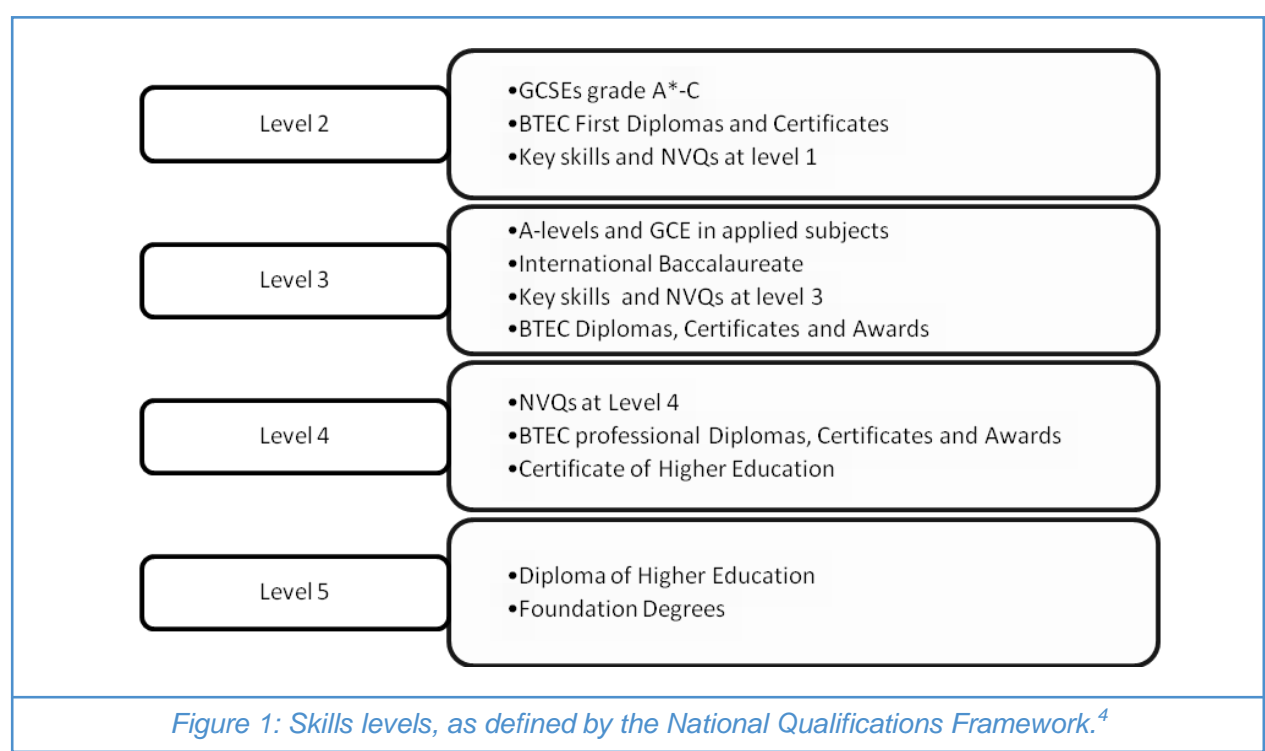


The level of upskilling described in the Leitch Review means that a greater partnership between educational institutions and employers is required. Levels 4 and above are of interest for $\mathrm{HEls}$ where collaboration with industry is traditionally not common.

The following recommendations are reproduced directly from the Review of Skills: ${ }^{2}$

- 'Increase adult skills across all levels.'

- 'Route all public funding for adult vocational skills in England, apart from community learning, through Train to Gain and Learner Accounts by 2010.

- 'Strengthen employer voice.'

- 'Increase employer engagement and investment in skills.'

- 'Launch a new "Pledge" for employers to voluntarily commit to train all eligible employers up to Level 2 in the workplace.'

- 'Increase employer investment in Level 3 and 4 qualifications in the workplace.'

- 'Increase people's aspirations and awareness of the value of skills to them and their families.

- 'Create a new integrated employment and skills service.'

The Leitch Review anticipates that Sector Skills Councils (SSCs) play an integral role in the approval of vocational qualifications. This allows for cooperation between employers and SSCs to produce qualifications that benefit industries. These courses may be delivered at established institutions and may include work-based learning qualifications and will attract public funding. ${ }^{2}$

The 2009 Skills for Growth report highlights and reiterates the importance of increasing the standard and number of technicians within industry, ${ }^{3}$ increasing the number of formalised qualifications obtainable particularly through apprenticeships.

\section{Work-based learning}

What is work-based learning?

It is widely being acknowledged that work-based learning (WBL) strategies are a vital part of the ongoing and future development of the existing workforce. For example, in Europe the Developing European Work Based Learning Approaches and Methods (DEWBLAM) project ${ }^{5}$ intended to develop a Europe-wide network of models and approaches to WBL within a European consortium of establishments, with the aim of allowing access to Higher Education qualifications for those adults currently in employment, through accreditation of prior and experiential learning.

\section{Defining work-based learning}

A broad definition of WBL is offered in Work-based learning: A New Higher Education ${ }^{6}$ where the authors expand upon their definition to include meeting the requirements of learners and the contribution that this learning will have in the development of the organisation in the long term: ${ }^{6}$

"Work-based learning is the term being used to describe a class of university programmes that bring together universities and work organizations to create new learning opportunities in workplaces. ${ }^{, 6}$
Whereas Gray identified three key elements to work-based learning to which all learners and employees can relate:

"A definition for the higher education level could involve any of the following work-based learning types: learning through work, learning for work and learning at work." ${ }^{7}$

A further definition of work-based learning was provided by Sodiechowska and Miasch:

“.. where students are full-time employees whose programme of study is embedded in the workplace and is designed to meet the learning needs of the employees and the aims of the organisation."

With respect to pedagogy, the practice of work-based learning can be considered to be the continued lifelong learning adults undertake throughout their lives, following education $;^{9}$ and in an educational environment. Work-based learning is a widely utilised tool employed by both HEls and businesses to educate and develop their students or work-force in all three elements outlined above. ${ }^{7}$

There are many traditional WBL pathways involved throughout the education system, as well as in higher education institutions and businesses, as there are many means by which the student is engaged and assessed. Using the definition above, the following collection of approaches was compiled to illustrate the three types of learning.

\section{Learning for work}

Learning for work can involve the high-school student embarking on a two-week work-experience placement, whereby they would be involved, albeit very superficially, in the processes of the workplace, reporting on how they developed over their time.

A further example is the long-established sandwich-course observed in $\mathrm{HE}$, with students spending a year within industry carrying out a more significant role within their company (for example in science-based industries an involvement in new product or existing product development), applying their theoretical knowledge in a working environment while being assessed as part of their degree course.

Teacher training courses such as the Post-Graduate Certificate of Education (PGCE) or Graduate Teacher Programme (GTP) routes which involve professional development of a learner with a means of training specifically for a certain job are also learning for work. Teacher training courses are available as purely work-based programmes, as is the case for the GTP or School-Centred Initial Teacher Training (SCITT) courses. The PGCE route offers work placements to assist in the learning for work, as well as combining the principles of pedagogy and classroom management through educational institutions, with subject specific work. All routes require each learner to collate a portfolio of evidence throughout their time within the workplace.

\section{Learning at work}

A commonplace example of learning at work is the similarly well-established on-site company training schemes and programmes which can provide a means of upskilling the 
existing workforce without the need for lengthy periods of time away from work, taught by an experienced senior technical expert employee or an external consultant from a specialist company. In general, these courses are not often formally assessed or given accreditation.

An example of an off-site training scheme is the Introduction to Aerosol Technology, ${ }^{10}$ designed and run by the British Aerosol Manufacturers' Association (BAMA) to train and educate industries and employees on aerosol technologies without accreditation. This course provides a good example of prior learning through which accreditation could be awarded.

\section{Learning through work}

There are examples whereby completion of on-site training courses are formally assessed and accredited (these are examples of learning through work) as well as accredited day-release programmes through further and higher education institutions.

\section{Approaches to work-based learning}

There are many recognised courses throughout the UK which involve aspects of WBL and there are several universities with established WBL departments, with courses that can cater specifically for the individual as well as for their industry.

A recent paper by Lineham and Sheridan ${ }^{11}$ delves quite extensively into workplace learning courses offered within Irish third-level colleges (UK - HE equivalence), to deliver new provisions for workplace learning programmes. Lineham and Sheridan surveyed seven HEls for a total of 433 courses, of which 221 were designed by the institution alone, 47 as part of a collaboration between the institution and industry and only 10 designed by industry. ${ }^{11}$

It was found that learners using a work-based approach learn from their community of practice in their workplace as well as from their work-based learning peers at the university. ${ }^{12}$

A study by Rhodes and Shiel ${ }^{13}$ aimed to discover how work-based projects promote learning for the worker and their organisation. The research outlines through case studies how work-based projects have been utilised successfully by Northumbria University. The same review involves an in-depth look at the WBL courses that are running at Northumbria University where they highlighted principles which are based on those described by Boud: ${ }^{6}$
- A partnership between organisation and university to foster learning.

- Learners are employed/in a contractual relationship with the external organisation.

- The programme followed derives the needs of the workplace and the learning: work is the curriculum.

- Learners engage in a process of recognition of current competencies prior to negotiation of a programme of study.

- A significant element of the programme is through learning projects undertaken in the workplace.

- The University assesses the learning outcomes against a trans-disciplinary framework of standards and levels.

These points can be further reinforced by Bragg and Hamm, who identified a set of criteria for the success of WBL courses: ${ }^{14}$

- Strong Programme leadership.

- Exclusive connections between the programme and its environment (niche market).

- Frequent and effective communications with local employers.

- Beliefs about programme excellence.

- Effective school-based learning component.

- Adequate financial support.

- Innovative programme and pedagogical features.

The Higher Education Academy (HEA) Centre for Education in the Built Environment (CEBE) has released a series of guides under the title 'Employer Engagement', sharing guidelines and case studies for the involvement of employers in the design of courses. Figure 2 shows the continuum of ways in which WBL can be delivered. ${ }^{15}$ Examples 1 and 2 show two variations in the work-based theme, with the emphasis changing from teacher-centred learning (example 2) to student centredlearning (example 1); both examples allow for the delivery of courses by blended learning. In the guidelines set out by CEBE, example 1 is of a tutor travelling to various employer establishments delivering content by a face-to-face means, but this could readily be adapted for distance learning.

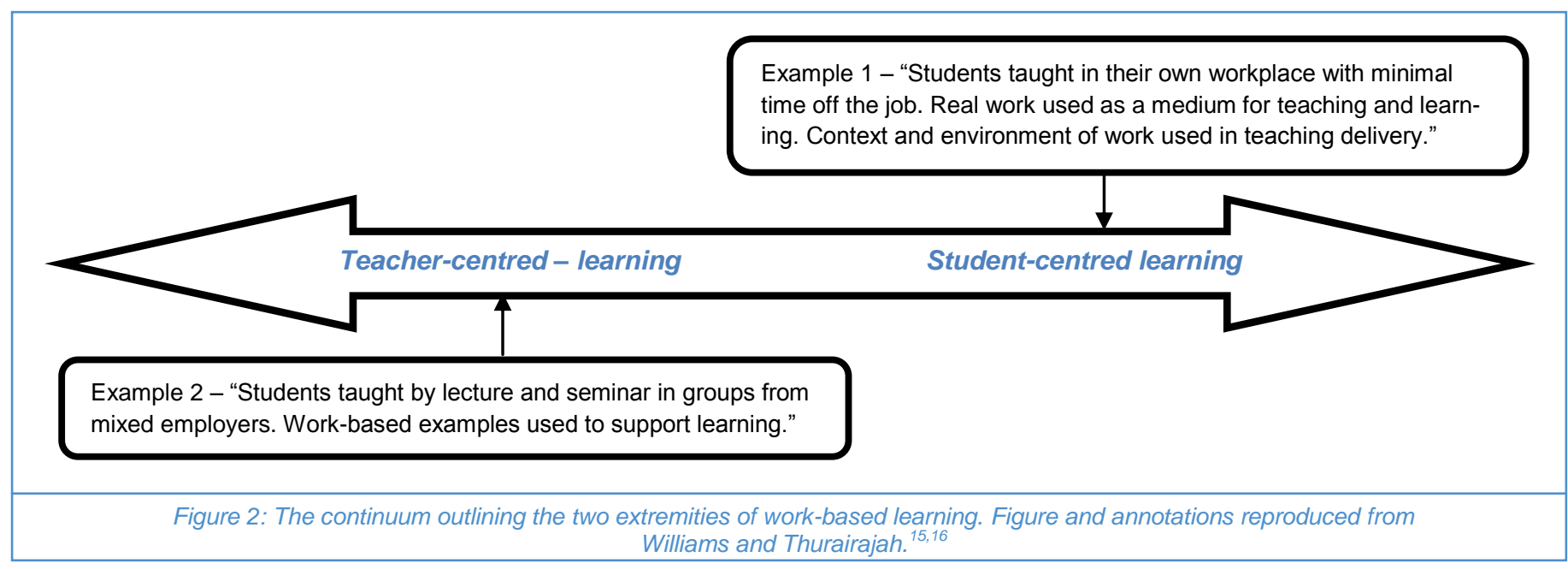


Why conduct work-based learning as either part of, or most of a course?

Most literature on the subject advocates an individualised approach for the learner whilst maintaining contact between academy and employer to assist in development of the learning plan and also satisfying the requirements of the employer; the employer involved should have a lot more input into the design and outcomes of their learners' course structures. $^{12}$

The Learn Direct agency allows for further education and training for the existing workforce, with courses designed around the learners' requirements to fit in around their work-life with their 'Learning through Work' programmes designed specifically for such needs. Several courses run in partnership with the University of Derby.

With respect to the relation of work-based learning to organisations and employers, a quote from Clarke and Copeland states that:

'Work based learning is commonly taken to refer to structured learning opportunities which derive from, or which are focused on, the work role of individuals within organisations. $^{, 17}$

The definition above provides a foundation for the new learning being based on requirements of the workplace, through collaboration between universities and work organisations, whilst incorporating underpinning knowledge and focusing these into a real world, work-related problem. ${ }^{17}$ This allows for the development of a combination of the relevant foundation of science knowledge complemented by the learning opportunities available through the workplace.

Different models of work-based learning

How are the WBL aspects of a programme approached and delivered?

Several different courses and HEls will be reviewed, determining whether there are any common aspects which can be built upon.

Brennan and Little define one way of constructing work-based learning courses:

'Curriculum controlled by higher education institution, content designed with employer - learner primarily full-time employee. ${ }^{18}$

The courses are designed with input from employers, with the framework arising from the pre-established subject discipline structure, with credits gained from modules within the course and also from accreditation of prior learning; which involves the assessment of learning gathered from work itself. Foundation Degree Forward (fdf) has published a series of detailed guides on their website (available online: $<w w w$. fdf.ac.uk/>) relating to all aspects of structuring a work-based learning course as well as engaging with employers. Two specific guides (Work-based Access to Higher education [Course Development Checklist] and Work-based Access to Higher Education [Guidelines]) relate to the development of foundation degree courses that include work-based learning. The second guide highlights the need for the effective development of work-based learning and work-related skills: ${ }^{19}$
Work-based learning skills:

- Develop solutions to workplace problems drawing on theory and practice.

- Exploit the workplace as a learning resource.

- Manage oneself (and others).

- Reflect on what has been learnt in and from the workplace.

- Transfer existing knowledge, capabilities and competences to new or different contexts.

Work-related skills:

- Action planning.

- Contribute to meetings.

- Entrepreneurship.

- Goal setting.

- Negotiating.

- Networking.

- Project management.

- Self-appraisal.

- Team working.

- Using, and acting as, a consultant.

The two lists describe different sets of skills: the work-related skills describe transferable skills which are both desirable and advantageous for all employees, whereas work-based learning skills involve the learner drawing upon subject knowledge and theory, combined with their experience, to utilise the workplace in personal development. During course development, care should be taken to include the introduction and development of all the aforementioned skills within work-based learning modules, whether they are theory or skills based.

In the view of these sectors, how relevant is this form of learning?

A paper by Foundation Degree Forward examines in depth the need for developing higher skills in the work force and outlines significant positives in the successful implementation of foundation degrees. ${ }^{20}$ Publishing benefits to employer, student and HE establishment it also defines a list of key potential perceived benefits to entice employers toward collaboration with universities to train their workforce: ${ }^{20,21}$

- Better quality recruits.

- Flexible entry requirements.

- Flexible, tailored to your needs.

- Improved workforce performance and productivity.

- Increased employee motivation - higher staff retention.

- Meets skills shortages - grow your own workforce.

- Work-based learning - little time off the job, minimal disruption.

- Projects directly related to your business.

- You [the employer] are closely involved in the delivery.

- Potential to accredit company training programmes.

- Extremely good value compared to private sector training.

- Direct links to further qualifications and continuing professional development. 
This list is by no means definitive. However it does provide an enticing spectrum of positive aspects for employers tempted to develop their workforce with work-based learning courses.

\section{Implementation of Work-Based Learning}

Lineham and Sheridan summarise key points for both employers and HEls when considering the implementation of work-based learning modules and courses: ${ }^{11}$

HEls:

- Ensure that recognition of prior learning is an integral component.

- Establish strong industry partnerships.

- Involve the employer in the development of the programme; especially when designing work-based projects and assignments.

- Develop customised programmes; allows for the expectations and needs of both employee and employer to be met.

\section{Employers:}

- Encourage employees to engage in skills development.

- Allocate workplace mentor to assist the learner

- Encourage employee responsibility toward their personal professional development.

- Develop work-based projects and assignments with sense of purpose.

These short checklists provide a foundation through which institutions and employers can abide by in an attempt to coordinate with one another during the development of specialised courses and modules.
Accreditation of prior and experiential learning

Even though the continual learning at and through work is considered learning from a theoretical perspective, it is often overlooked because of its informal nature. ${ }^{9}$ Boud and Middleton believe that a recognition of this learning would allow for an enhancement in the work and the quality of working life. ${ }^{9}$ For adults re-entering education there is often a wealth of prior experience they can reflect upon and it is becoming more accepted that this experience requires acknowledgement. Hence, a demand has arisen for Accreditation of Prior Learning (APL) for previously assessed learning and Accreditation of Prior Experiential Learning (APEL) in which the knowledge is gained by experience and presented for accreditation.

Systems of APL are established worldwide, with unique acronymic titles depending on the country (Figure 3 .) It is widely being acknowledged that such recognition of learning steers higher education toward the industrial and business world. ${ }^{22}$ However it should not be used or marketed as a fast-route to a qualification. A survey of 433 courses at seven higher education colleges in Ireland showed that 264 out of 433 courses gave credit and recognition for prior learning, a total of $61 \% .^{11}$

There are distinctions between APL and APEL. As mentioned APL involves organised learning through which assessment or certification has taken place. The learning through APEL is related to skills, learning and knowledge gathered through experiences in the learner's work, or life, which involves no certification. Both systems gather evidence relating to the learning as opposed to the experience. ${ }^{23}$

\begin{tabular}{|c|c|}
\hline Pre-entry & $\bullet$ Marketing of availability of APL \\
\hline Candidate profiling & $\bullet$ \\
\hline Providing evidence & $\bullet$ Establish candidate goals and past experience \\
\hline Accreditation & $\bullet$ Claim checked and verified \\
\hline Post APL counselling & $\bullet$ Endorsement by institution \\
\hline
\end{tabular}

\begin{tabular}{|c|c|}
\hline Identify & -Identify HE level learning acquired through life/work \\
\hline Articulate & -Show relevance to degree course \\
\hline Document & -Verify and provide evidence \\
\hline Measure & -Determine extent of learning acquired \\
\hline Evaluate & -Decide if learnings meet acceptable standard and credit equivalence \\
\hline Transcribe & - Record recognition of learning \\
\hline
\end{tabular}

Figure 3: UK and American models (respectively) for the accreditation of prior learning. ${ }^{23}$ 
The most common method by which to assess and accredit prior learning is by the employee/learner providing an in depth portfolio of evidence through which they demonstrate developed skills and knowledge gained. This process may be easier for prior learning, due to the increased formal nature of certified training courses.

The steps required in the development of a portfolio can be based on the both the UK and American APL models as depicted in Figure $3 .^{23}$

The book 'Good Practice in the Accreditation of Prior Learning ${ }^{23}$ by Nyatanga gives an extensive overview into good practice of the assessment of prior and experiential learning.

\section{Perceived Problems}

Developing work-based learning for incorporation into an academic qualification will not be without issues, below is a selection of potential issues that may arise for each partner.

What issues may arise from this collaboration from the $H E$ point of view?

- Potential shift from traditional, teaching methods, including the incorporation of a larger proportion of blended learning or wholly work-based modules than is generally common.

- Due to the work-based aspects, the quality of student experience could differ between workplace establishments, arising from variables that are not within the control of the $\mathrm{HEI}$.

- The increased involvement of the employer in designing the courses could lead the $\mathrm{HEI}$ to perceive a reduction in control over the subject content and its quality.

- The flexible nature of the course can lead to individual learning contracts for different students. Thus flexible learning outcomes must be negotiated. This also relates to the inconsistency of student experience.

- Issues may arise over the identity of the assessor of the work-based learning modules and projects; if supervisors or mentors are provided in the workplace they may be involved in the assessment, or the employer may encourage independent assessors for sections of the course which they helped to develop.

- Support for students in the workplace, or lack thereof; workplace supervisors may not be able to dedicate the time the learner needs, this may impact on course completion and attainment.

- All courses are modular but providers may not have the administrative and financial infrastructure to allow involvement by module rather than by programme.
What issues may arise from this collaboration from the employer point of view?

- Issues may arise through perceived irrelevancies of some content in relation to specific industries, potentially arising from a lack of industrial input into the course structure or the specialist modules.

- The fast upgrading of technologies throughout all industries, coupled with a slow throughput of employees completing the course, may result in technical skills superseded upon graduation.

- Employers reluctant to release students for long periods of time. This can impinge on day-release or block learning as well as the work-based elements.

- Time and money may be required to support the work-based learning courses and modules within the workplace. Employers may mistakenly see these as 'resource free'.

- The balance between job-specific learning and obtaining a broader science education which may equip students for employment in another sector.

What issues may arise from this collaboration from the student point of view?

- Work-based learning modules could increase the learner's workload too much both in and outside the workplace.

- Learners may find that not obtaining their desired levels of support from both higher education and employers may pose a problem, as well as not knowing who to seek advice from.

- Too little collaboration between higher education establishment and employer; neither establishment sure who is the main contact for assistance with work-based learning modules.

- Module outlines and learning outcomes may be too diffuse if they are flexible enough for all students.

- Ensuring the students feel as though they are part of a community of learners.

- Inadequate focus on individualised learning outcome or study plan.

- Perceived irrelevance of certain topics over which they may have no control.

- The balance between job-specific learning and obtaining a broader science education which may equip them for employment in another sector.

The list of anticipated issues outlined above will not be exhaustive. Other potential problems may arise during the implementation of work-based learning and attempts should be made to tackle any issues which may arise to the satisfaction of all groups. 


\section{Conclusions}

Work-based learning

Although there are many ways to describe and define work-based learning, the definition provided by Gray ${ }^{7}$ provides three key umbrella categories under which can be encompassed the many models of work-based learning:

'A definition for the higher education level could involve any of the following work-based learning types; learning through work, learning for work and learning at work., ${ }^{7}$

The methods by which work-based learning courses can be developed are discussed in the literature, each definition or set of considerations building upon and reinforcing others. There is no rigid formula for designing work-based modules or resources. Merril's First Principles of Instruction provide a set of guidelines which lay the foundations for successful module development: ${ }^{24}$

- Learners are engaged in real-work problems.

- Existing knowledge is activated as a foundation for new knowledge.

- New knowledge is demonstrated to the learner.

- New knowledge is applied by the learner.

- New knowledge is integrated into the learner's world.

\section{References}

1. Cogent (2008), Skills for Science Industries: Skills at work.

2. Leitch L. (2006), HM Treasury.

3. I. S. Department for Business, Skills for Growth: The national skills strategy (2009), Department for Business, Innovation \& Skills.

4. Direct.gov (2009), in Qualifications: what the different levels mean.

5. DEWBLAM (2003-2006), in Developing European Work Based Learning Approaches and Methods.

6. Boud D. and Solomon, N. (2001), Work-Based Learning: A New Higher Education?, Taylor \& Francis Inc.

7. Gray D. (2001), Assessment series, 11.

8. Sobiechowska P. and Maisch M. (2006), Educational Action Research, 14, 267.

9. Boud D.and Middleton H. (2003), Journal of Workplace Learning, 15, 194.

10. BAMA (2009), in 'Introduction to Aerosol Technology'.

11. Lineham M. and Sheridan I. (2009), Journal of Workplace Learning, 21, 496.

12. Siebert S., Mills V., and Tuff C. (2009), Journal of Workplace Learning, 21, 443.

13. Rhodes G. and Shiel G. (2007), Journal of Workplace Learning, 19, 173.

14. Bragg D. and Hamm R., (1996).

15. Williams A. and Thurairajah N. (2009), Work-based Learning: Working the Curriculum: Approval, Delivery \& Assessment, University of Salford.

16. Williams A. and Lees T. (2009) Knowing your Market: Strategy, Communication and Relationships, University of Salford.

17. Clarke D. J. and Copeland L. (2003), Nurse Education in Practice, 3, 236

18. Brennan J. and Little B. (1996), Sheffield: Department for Education and Employment.
Education course.

20. FDF (2009), Developing higher skills in the UK workforce: A guide to collaboration between higher education and employers.

21. Anderson A. and Hemsworth D. (2005), From Apprenticeship to Higher Education - A guide to developing work-based progression routes to higher education for Advanced Apprentices and other skilled staff and managers.

22. Spencer B. (2005), Encyclopaedia of Adult Education, 508.

23. Nyatanga L., Forman D., and Fox J. (1998), Good practice in the accreditation of prior learning, Continuum Intl Pub Group.

24. Merrill M. (2002), Educational technology research and development, 50, 43

19. FDF (2008), Developing Work-based Access to Higher 